\title{
Epidemiology of attention-deficit/
} hyperactivity disorder (ADHD) in children and adolescents in Africa: a systematic review and meta-analysis

\author{
Getinet Ayano ${ }^{1,2^{*}}$, Kalkidan Yohannes $^{3}$ and Mebratu Abraha ${ }^{4}$
}

\begin{abstract}
Background: Attention-deficit/hyperactivity disorder (ADHD) is the most common neurodevelopmental disorders in childhood and adolescence, affecting 2.2 to $17.8 \%$ of all school-aged children and adolescents. ADHD in children has been associated with a wide range of developmental deficits including limitations of learning or control of executive functions as well as global impairments of social skills. However, no review has been conducted to report the consolidated magnitude of ADHD in children and adolescents in Africa. Therefore, this systematic review and meta-analysis aimed to estimate the prevalence of ADHD in Africa.
\end{abstract}

Methods: Following the PRISMA guideline, we systematically reviewed and meta-analyzed studies that investigated the prevalence of ADHD in Africa from three electronic databases (PubMed, Embase, and Scopus). We also looked at the reference lists of included studies to include other relevant studies. Subgroup and sensitivity analysis was carried out based on the study setting, tools used to measure ADHD, sex of participants, and the subtype of ADHD. Heterogeneity across the studies was evaluated using Cochran's $Q$ - and the $R^{2}$-test. We assessed potential publication bias using Egger's test and visual inspection of the symmetry in funnel plots.

Results: In the present meta-analysis, 7452 articles were initially identified and evaluated. Of these, 12 studies that met the inclusion criteria were included in the final analysis. The pooled prevalence of ADHD in children and adolescents in Africa was 7.47\% (95\% Cl 60-9.26). The prevalence of ADHD was apparently greater in boys (10.60\%) than in girls (5.28\%) with a male:female ratio of 2.01:1. In our subgroup analysis, the predominantly inattentive type (ADHD-I) was found to be the most common subtype of ADHD, followed by hyperactive-impulsive type (ADHD-HI) and the combined type (ADHD-C) with the prevalence of $2.95 \%, 2.77 \%$, and $2.44 \%$ respectively. The predominantly inattentive type (ADHD-I) was the most common type of ADHD in both boys (4.05\%) and girls (2.21\%). The funnel plot and Egger's regression tests provided no evidence of substantial publication bias in the prevalence of ADHD.

Conclusion: Our systematic review suggested a higher prevalence of ADHD (7.47\%) in children and adolescents in Africa, indicating that ADHD is a serious public health problem in children and adolescents in Africa. The prevalence of ADHD was considerably greater in males than in females. The predominantly inattentive type (ADHD-I) was the most common type of ADHD in both males and females. Greater attention needs to be paid to the prevention and treatment of ADHD.

\footnotetext{
*Correspondence: babiget2015@gmail.com

${ }^{1}$ Research and Training Department, Amanuel Mental Specialized Hospital, Addis Ababa, Ethiopia

Full list of author information is available at the end of the article
}

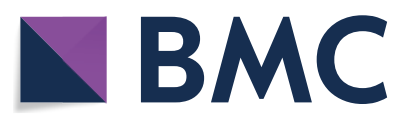

(c) The Author(s) 2020. This article is licensed under a Creative Commons Attribution 4.0 International License, which permits use, sharing, adaptation, distribution and reproduction in any medium or format, as long as you give appropriate credit to the original author(s) and the source, provide a link to the Creative Commons licence, and indicate if changes were made. The images or other third party material in this article are included in the article's Creative Commons licence, unless indicated otherwise in a credit line to the material. If material is not included in the article's Creative Commons licence and your intended use is not permitted by statutory regulation or exceeds the permitted use, you will need to obtain permission directly from the copyright holder. To view a copy of this licence, visit http://creativeco mmons.org/licenses/by/4.0/. The Creative Commons Public Domain Dedication waiver (http://creativecommons.org/publicdomain/ zero/1.0/) applies to the data made available in this article, unless otherwise stated in a credit line to the data. 
Keywords: Attention-deficit/hyperactivity disorder, Epidemiology, Africa, Children, Systematic review and metaanalysis

\section{Background}

The Diagnostic Statistical Manual of fifth revision, DSM-5, defines ADHD as a neurodevelopmental disorder characterized by impairing levels of inattention, disorganization, and/or hyperactivity-impulsivity [1]. Inattention and disorganization involve failure to stay on task, seeming not to listen, and losing materials, at levels that are not consistent with age or developmental level $[1,2]$. Hyperactivity-impulsivity entails overactivity, fidgeting, inability to stay seated, intruding into other people's activities, and inability to wait-symptoms that are excessive or age or developmental level $[1,2]$.

In childhood, ADHD frequently overlaps with other mental disorders including oppositional defiant disorder and conduct disorder [3, 4]. ADHD often persists into adulthood, with resultant impairments of social, academic, and occupational functioning $[2,5]$.

In DSM-5, three main nominal subtypes of ADHD are identified which are mainly based on the differential elevation of two dimensions of inattention symptoms and hyperactivity-impulsivity symptoms. The first one is the predominantly inattentive type (ADHDI) which describes individuals with maladaptive levels of inattention, but not hyperactivity-impulsivity; the second is the predominantly hyperactive-impulsive type (ADHD-H) which is characterized by maladaptive levels of hyperactivity-impulsivity, but not inattention, and finally, the combined type (ADHD-C) which describes individuals who exhibit significant symptoms of both inattention and hyperactivity-impulsivity [2].

In a recent meta-analysis which included 179 ADHD prevalence estimates, the pooled prevalence estimate of ADHD in children and adolescents was 7.2\% (95\% confidence interval: 6.7 to 7.8 ) [1]. However, the prevalence of ADHD in adults is lower than the corresponding prevalence estimate in children and adolescents. For example, in one meta-analysis study done in 2009, the pooled prevalence estimate of adult ADHD was 2.5\% (95\% CI 2.1-3.1) [6]. Nevertheless, the reported prevalence showed a significant vibration across the studies ranging from 2.2 to $17.8 \%$ [7-9].

According to evidence from different worldwide scientific studies, among the three nominal subtypes of ADHD, the predominantly inattentive type (ADHDI) is the most common subtype of ADHD, followed by combined (ADHD-C) and hyperactive-impulsive type (ADHD-HI) [4, 10-15]. ADHD-I subtype is the most prevalent subtype of ADHD in girls than in other ADHD subtypes [4, 10-15]. Epidemiological evidence also suggests that ADHD is more prevalent among males in all three subtypes [4, 11-13, 16-18].

To our knowledge, this is the first systematic and meta-analytic review that aimed to estimate the prevalence of ADHD in children and adolescents in Africa. We hypothesized that the prevalence of ADHD is notably high in children and adolescents in Africa. Therefore, the purposes of this meta-analysis are (1) estimate the overall prevalence of ADHD in Africa; (2) determine the prevalence of specific subtypes of ADHD in Africa; (3) formulate recommendations for future clinical practice and research as well as provide evidence for planners and policymakers in the area.

\section{Methods/design}

We conducted this review following the Preferred Reporting Items for Systematic Reviews and Meta-Analyses (PRISMA) guidelines [19]. We used two strategies to identify studies-systematic search from the three electronic databases (EMBASE, PubMed, and Scopus) and hand search of the reference lists of the included studies. The following terms and keywords were applied for searching relevant studies in PubMed: (Epidemiology OR prevalence OR magnitude OR incidence) AND (ADHD OR attention deficit hyperactivity disorder OR behavioral disorder OR neurodevelopmental disorder) AND Africa. The remaining two databases (EMBASE and SCOPUS) were searched using database-specific subject headings related to the above keywords used in PubMed. No date limit was applied.

\section{Eligibility criteria}

An article was included if it met the following criteria: first, the study was conducted in children, (2) study design was observational studies (cross-sectional and case-control study design), (3) the outcome of interest was ADHD, and (4) conducted in Africa. We excluded editorials, reviews, nonhuman subjects, and not published in the English language. We screened titles and abstracts using the prespecified inclusion and exclusion criteria before the retrieval of full-text articles for further screening. Two reviewers (KY and MA) independently performed the screening. In the second step, the two reviewers independently read the full-texts of the articles that are not excluded in the initial stage, then selected the studies that met the inclusion criteria. Any disagreements 
were resolved by consensus or after discussing it with a third reviewer.

\section{Methods for data extraction and quality assessment}

Two authors (KY and MA) independently extracted the information from the included studies. We used a specific data extraction form particularly designed to extract data for this systematic review and meta-analysis. Data from the included studies were extracted to summary tables containing information on the study population, sample size, s year of publication, study design, study setting, authors, and the tools used for assessment of ADHD. Information from the included studies was extracted as depending on the assessment template prepared as recommended by PRISMA guidelines [20].

We used a modified version of the Newcastle-Ottawa Scale (NOS) to evaluate the quality of the studies included in our final analysis [21]. The NOS scale assesses quality in several domains: sample representativeness and size, comparability between participants, ascertainment of cases and statistical quality.

\section{Definition of outcome (ADHD)}

In this study, the definition of our outcome variable (ADHD) was based on validated standard instruments designed to measure ADHD in children and adolescents. Hence, studies included in the final analysis used the following standard tools to assess ADHD: Disruptive Behavior Rating Scale (DBRS) [22], Conners-Wells Adolescent Self-Report Scale (CASS) [23], Diagnostic interview for Child and Adolescents-Revised (DICA-R) [24], Swanson, Nolan, and Pelham rating scale 4th revision (SNAP-IV-C) [25], the Vanderbilt ADHD Teacher Rating Scale (VARTRS) [13], ADHD rating scale [26], and the Diagnostic and Statistical Manual of Mental Disorders, Fourth Edition, Text Revision (DSM-IV) [27].

\section{Data synthesis and analysis}

For the studies that reported suitable statistics, a metaanalysis with a random-effects model was conducted to calculate pooled prevalence, and 95\% CIs [28]. We used comprehensive meta-analysis software version 3 to pool the estimates from the included studies. We assessed heterogeneity using $Q$ and $I^{2}$ statistics [28]. The $I^{2}$ statistics assess the proportion of total variance across the included studies that contributed to the observed heterogeneity. In this study, the $I^{2}$ statistic value of zero indicates true homogeneity, whereas the values 25,50 , and $75 \%$ were considered to represent low, medium, and high, respectively [29]. For the data identified as heterogeneous, a random-effects model was used during analysis. A leave one-out sensitivity analysis was carried out to evaluate the key studies that exert a major impact on between-study heterogeneity. In addition, to further identify the possible source of heterogeneity among the studies we conducted the subgroup and sensitivity analysis based on the gender of the participants, the study setting, the tools used to measure ADHD, and the quality of the included studies. Publication bias was assessed by funnel plot and Egger's regression tests. Analyses with $\mathrm{P}<0.05$ were interpreted as significant.

\section{Results \\ Identification of studies}

A total of 7484 articles were identified using electronic search engines and strategies. An additional eight relevant studies were found through a manual search of the reference lists of the remaining papers. Of these, 7452 were excluded due to duplicate and during the review of abstract and titles as they did not meet the inclusion criteria (Fig. 1). 40 articles with full texts were retrieved for further screening and 28 of these were excluded.

\section{Characteristics of included studies}

Twelve studies were included in the systematic review and meta-analysis. The characteristics of these studies are summarized in Table 1 . Selected studies were conducted in Nigeria [30-32], Sudan [33], Uganda [34], Congo [35], Kenya [36, 37], Egypt [38-41], and Ethiopia [42]. Age at diagnosis of ADHD varies from 4 to 18 years. Five studies DBRS $(27,24,25,28,34)$ to assess ADHD, one used CASS (33), one used DICA-R (35), one used SNAP-IV$C$ (26), one used VARTRS (23), one used ADHD rating scale (31), and two used DM-IV $(29,32)$. The sample size of the included studies ranged from 100 to 1477 . Ten studies were good in quality, one moderate (31), and one poor (34).

\section{Quality assessment}

The quality of the studies was assessed using the Newcastle-Ottawa Scale with some modifications. Ten studies were good in quality $(23-30,32,33,35)$, one moderate (31), and one poor (34) (see Table 1).

\section{The prevalence of ADHD in children (meta-analysis)}

A meta-analysis of 12 prevalence studies (nine population-based prevalence studies and three clinical samples) performed in Africa between 2005 and 2017, and revealed that the pooled prevalence of ADHD in children and adolescents was 7.47\% (95\% CI 6.00-9.26) (Fig. 2). The result showed a significant heterogeneity across all studies $\left(I^{2}=90.29 \% ; Q=114.25, d f=11, P<0.001\right)$. The pooled prevalence was based on the random effect model due to the observed heterogeneity across the studies. 


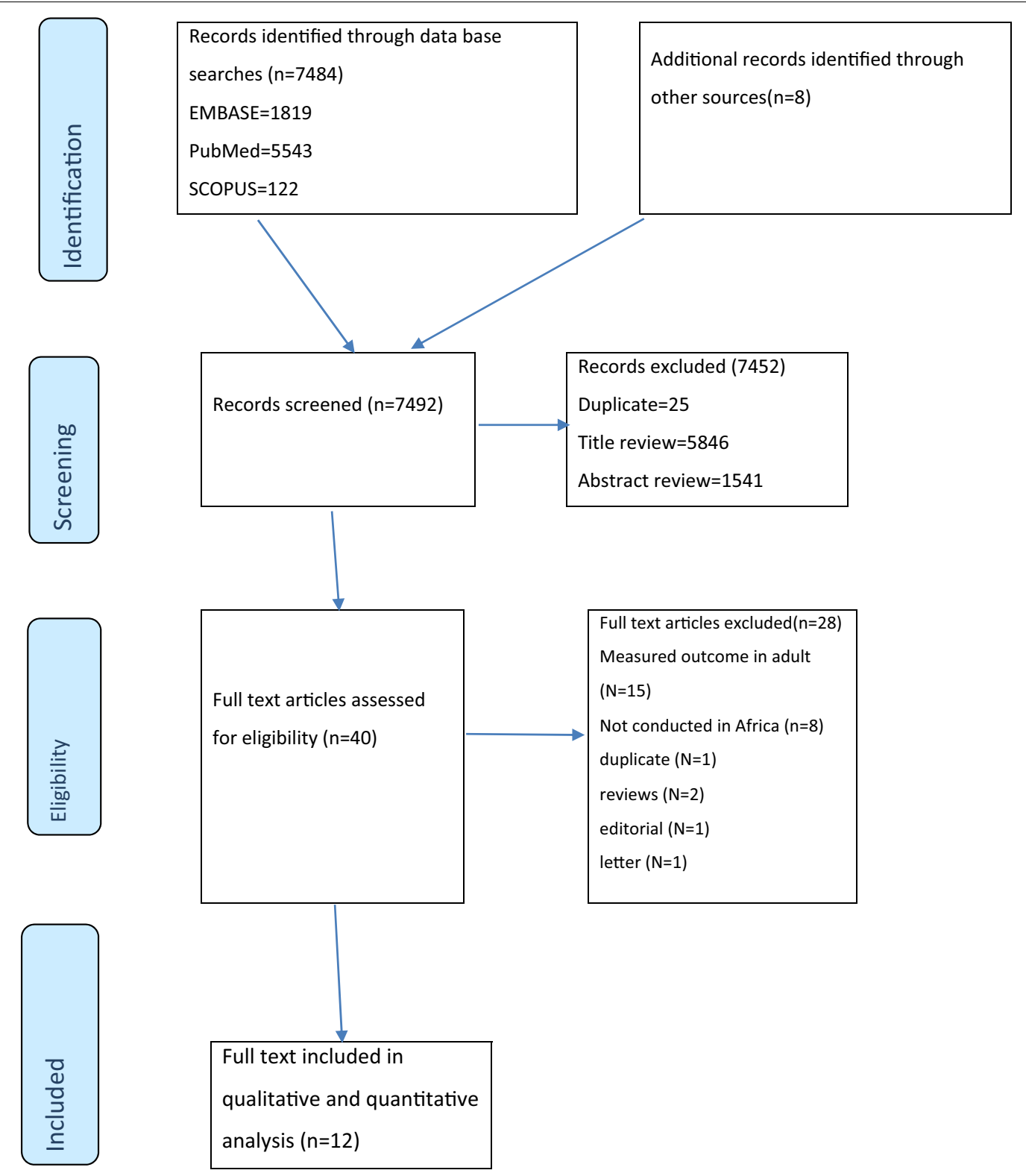

Fig. 1 PRISMA flowchart of review search

\section{Sensitivity and subgroup analysis}

Given a considerable heterogeneity across the included studies in the meta-analysis, we performed a sensitivity analysis to better understand the source of heterogeneity (Table 2). There was no considerable difference in the subgroups based on study setting or locations as well as nominal types of ADHD and tools used to measure ADHD. However, we identified a significant heterogeneity by gender for overall as well as subtypes of ADHD.

\section{Gender difference in the prevalence of ADHD in children}

A meta-analysis of seven studies that reported data on each gender showed that the prevalence of ADHD in males was substantially higher than the magnitude of AGHD in females. The pooled prevalence of ADHD was found to be $10.60 \%$ (95\% CI 9.05-12.38) in males and it was $5.28 \%$ (95\% CI $4.38-6.36 \%$ ) in females. The difference between the groups was statistically significant (see Table 2). 
Table 1 Characteristics of included studies

\begin{tabular}{|c|c|c|c|c|c|c|}
\hline $\begin{array}{l}\text { Author (year) } \\
\text { (reference number) }\end{array}$ & Country & $\begin{array}{l}\text { Sample } \\
\text { size }\end{array}$ & Setting & Tool used & Prevalence of ADHD & $\begin{array}{l}\text { NOS } \\
\text { quality } \\
\text { score }\end{array}$ \\
\hline $\begin{array}{l}\text { Wamulugwa et al. } \\
\text { (2017) [13] }\end{array}$ & Uganda & 332 & $\begin{array}{r}\text { Hospital } \\
\text { based }\end{array}$ & DBRS & $\begin{array}{l}\text { Overall 11.75\% }(n / N=39 / 332) \\
\text { Men 14.9\% }(n / N=28 / 188) \\
\text { Women } 7.6(n / N=11 / 144)\end{array}$ & 8 \\
\hline Osman et al. (2015) [25] & Sudan & 1000 & $\begin{array}{l}\text { Schools and } \\
\text { community } \\
\text { based }\end{array}$ & SNAP-IV-C & $\begin{array}{l}\text { Overall 9.4\% }(n / N=94 / 1000) \\
\text { Inattentive type } 3.5 \%(n / N=35 / 1000) \\
\text { Impulsive type } 6.9 \%(n / N=69 / 1000) \\
\text { Combined type } \% 1.0(n / N=10 / 1000) \\
\text { Inattentive type in men } 4.9 \%(n / N=25 / 511) \\
\text { Inattentive type in women } 1.8 \%(n / N=9 / 489) \\
\text { Impulsive type in men } 9.6 \%(n / N=48 / 511) \\
\text { Impulsive type in women } 2.3 \%(n / N=21 / 489)\end{array}$ & 9 \\
\hline $\begin{array}{l}\text { Adewuya et al. (2007) } \\
\text { [22] }\end{array}$ & Nigeria & 1112 & $\begin{array}{l}\text { Schools and } \\
\text { community } \\
\text { based }\end{array}$ & VARTRS & $\begin{array}{l}\text { Overall } 8.7 \%(n / N=97 / 1112) \\
\text { Men } 11 \%(n / N=75 / 682) \\
\text { Women } 5.1(n / N=22 / 430) \\
\text { Inattentive type } 4.9 \%(n / N=55 / 1112) \\
\text { Impulsive type } 1.2 \%(n / N=13 / 1112) \\
\text { Combined type } \% 2.6 \%(n / N=29 / 1112) \\
\text { Inattentive type in men } 6.2 \%(n / N=42 / 682) \\
\text { Inattentive type in women } 3 \%(n / N=13 / 430) \\
\text { Impulsive type in men } 1.6 \%(n / N=11 / 682) \\
\text { Impulsive type in women } 0.5 \%(n / N=2 / 430) \\
\text { Combined type in men } 3.2 \%(n / N=22 / 682) \\
\text { Combined type in women } 1.6 \%(n / N=7 / 430)\end{array}$ & 8 \\
\hline $\begin{array}{l}\text { Ambuabunos et al. } \\
\text { (2011) [4] }\end{array}$ & Nigeria & 1473 & $\begin{array}{l}\text { Community } \\
\text { based }\end{array}$ & DBRS & $\begin{array}{l}\text { Overall } 7.6 \%(n / N=112 / 1473) \\
\text { Men } 9.4 \%(n / N=74 / 784) \\
\text { Women } 5.5(n / N=38 / 689) \\
\text { Inattentive type } 3.6 \%(n / N=53 / 1473) \\
\text { Impulsive type } 1.6 \%(n / N=24 / 1473) \\
\text { Combined type } \% 2.4 \%(n / N=35 / 1473) \\
\text { Inattentive type in men } 4.5 \%(n / N=35 / 784) \\
\text { Inattentive type in women } 2.6 \%(n / N=18 / 689) \\
\text { Impulsive type in men } 1.9 \%(n / N=15 / 784) \\
\text { Impulsive type in women } 1.3 \%(n / N=9 / 689) \\
\text { Combined type in men } 3.1 \%(n / N=24 / 784) \\
\text { Combined type in women } 1.5 \%(n / N=11 / 689)\end{array}$ & 9 \\
\hline Oforwe et al. (2009) [5] & Nigeria & 1384 & $\begin{array}{l}\text { Community } \\
\text { based }\end{array}$ & DBRS & $\begin{array}{l}\text { Overall } 8 \%(n / N=111 / 1384) \\
\text { Men } 9.5 \%(n / N=69 / 732) \\
\text { Women } 6.4 \%(n / N=42 / 652) \\
\text { Inattentive type } 2.7 \%(n / N=38 / 1384) \\
\text { Impulsive type } 3 \%(n / N=41 / 1384) \\
\text { Combined type } \% 2.5 \%(n / N=35 / 1384) \\
\text { Inattentive type in men } 3 \%(n / N=22 / 732) \\
\text { Inattentive type in women } 2.4 \%(n / N=16 / 652) \\
\text { Impulsive type in men } 3.2 \%(n / N=23 / 732) \\
\text { Impulsive type in women } 2.7 \%(n / N=18 / 652) \\
\text { Combined type in men } 3.6 \%(n / N=26 / 732) \\
\text { Combined type in women } 1.4 \%(n / N=9 / 652)\end{array}$ & 9 \\
\hline Kashala et al. (2005) [26] & Congo & 1187 & $\begin{array}{l}\text { Community } \\
\text { based }\end{array}$ & DBRS & $\begin{array}{l}\text { Overall } 6 \%(n / N=70 / 1187) \\
\text { Men } 7.1 \%(n / N=38 / 534) \\
\text { Women } 4.9 \%(n / N=32 / 653)\end{array}$ & 8 \\
\hline Wamithi et al. (2015) [27] & Kenya & 240 & Institution & DSM-IV & $\begin{array}{l}\text { Overall } 6.3(n / N=15 / 240) \\
\text { Inattentive type } 1.3 \%(n / N=3 / 240) \\
\text { Impulsive type } 2.9 \%(n / N=7 / 240) \\
\text { Combined type } \% 2.1 \%(n / N=5 / 240)\end{array}$ & 8 \\
\hline $\begin{array}{l}\text { Ashenafi et al. (2001) } \\
\text { [33] }\end{array}$ & Ethiopia & 1477 & $\begin{array}{l}\text { Community } \\
\text { based }\end{array}$ & DICA-R & Overall 1.49\% $(n / N=22 / 1477)$ & 8 \\
\hline $\begin{array}{l}\text { Awadalla et al. (2016) } \\
\text { [29] }\end{array}$ & Egypt & 873 & School based & $\begin{array}{l}\text { ADHD Rating } \\
\text { Scale }\end{array}$ & Overall $12.60(n / N=110 / 873)$ & 7 \\
\hline
\end{tabular}


Table 1 (continued)

\begin{tabular}{|c|c|c|c|c|c|c|}
\hline $\begin{array}{l}\text { Author (year) } \\
\text { (reference number) }\end{array}$ & Country & $\begin{array}{l}\text { Sample } \\
\text { size }\end{array}$ & Setting & Tool used & Prevalence of ADHD & $\begin{array}{l}\text { NOS } \\
\text { quality } \\
\text { score }\end{array}$ \\
\hline Farahat et al. (2014) [30] & Egypt & 1362 & $\begin{array}{l}\text { Community } \\
\text { based }\end{array}$ & DSM-IV & $\begin{array}{l}\text { Overall 6.9\% }(n / N=94 / 1362) \\
\text { Men } 10.9 \%(n / N=73 / 667) \\
\text { Women } 3 \%(n / N=21 / 695) \\
\text { Inattentive type } 2.6 \%(n / N=36 / 1362) \\
\text { Impulsive type } 1.3 \%(n / N=18 / 1362) \\
\text { Combined type } \% 2.9 \%(n / N=40 / 1362) \\
\text { Inattentive type in men } 3.4 \%(n / N=23 / 667) \\
\text { Inattentive type in women } 1.8 \%(n / N=13 / 695) \\
\text { Impulsive type in men } 2.2 \%(n / N=15 / 667) \\
\text { Impulsive type in women } 0.4 \%(n / N=3 / 695) \\
\text { Combined type in men } 5.2 \%(n / N=35 / 667) \\
\text { Combined type in women } 0.7 \%(n / N=5 / 695)\end{array}$ & 9 \\
\hline Bishry et al. (2014) [13] & Egypt & 925 & $\begin{array}{l}\text { Community } \\
\text { based }\end{array}$ & CASS & $\begin{array}{l}\text { Overall 9.4\% }(n / N=87 / 925) \\
\text { Men } 13.8 \%(n / N=58 / 421) \\
\text { Women } 5.8 \%(n / N=29 / 504) \\
\text { Inattentive type } 1.2 \%(n / N=11 / 925) \\
\text { Impulsive type } 4.4 \%(n / N=41 / 925) \\
\text { Combined type } \% 2.5 \%(n / N=23 / 925) \\
\text { Inattentive type in men } 2.3 \%(n / N=10 / 421) \\
\text { Inattentive type in women } 0.2 \%(n / N=1 / 504) \\
\text { Impulsive type in men } 8.8 \%(n / N=37 / 421) \\
\text { Impulsive type in women } 1.4 \%(n / N=7 / 504) \\
\text { Combined type in men } 2.9 \%(n / N=12 / 421) \\
\text { Combined type in women } 2.1 \%(n / N=11 / 504)\end{array}$ & 9 \\
\hline Yahia et al. (2014) [32] & Egypt & 100 & $\begin{array}{l}\text { Institution } \\
\text { based }\end{array}$ & DBRS & $\begin{array}{l}\text { Overall } 8 \%(n / N=8 / 100) \\
\text { Inattentive type } 4 \%(n / N=4 / 100) \\
\text { Impulsive type } 6 \%(n / N=6 / 100) \\
\text { Combined type } \% 2 \%(n / N=2 / 100)\end{array}$ & 5 \\
\hline
\end{tabular}

DBRS Disruptive Behavior Rating Scale, VARTRS The Vanderbilt ADHD Teacher Rating Scale, SNAP-IV-C Swanson, Nolan, and Pelham rating scale 4th revision, CASS Conners-Wells Adolescent Self-Report Scale, DICA-R Diagnostic interview for Child and Adolescents-Revised, VARTRS Vanderbilt ADHD Teacher Rating Scale, DSM-IV Diagnostic and Statistical Manual of Mental Disorders, Fourth Edition

\section{The prevalence of subtypes of ADHD in children}

We also performed subgroup analysis-based subtypes of ADHD. In our meta-analysis, among the three nominal subtypes of ADHD, the predominantly inattentive type (ADHD-I) was found to be the most common subtype of ADHD, followed by hyperactive-impulsive type (ADHD$\mathrm{HI}$ ) and combined (ADHD-C) with the prevalence of $2.95 \%, 2.77 \%$, and $2.44 \%$, respectively, although the difference across the groups was not statistically significant (see Table 2).

\section{Gender difference in the prevalence of subtypes of ADHD in children}

ADHD is more prevalent among males in all the three subtypes of ADHD, such as the predominantly inattentive type (ADHD-I), hyperactive-impulsive type (ADHD-HI), and combined (ADHD-C) with the prevalence of $4.05 \%$, $3.61 \%$, and $3.62 \%$, respectively, as compared to the corresponding prevalence in females of $2.21 \%, 1.5 \%$, and $1.52 \%$. The difference was statistically significant for inattentive and combined type but not for hyperactive type (see Table 2).
ADHD-I subtype is the most prevalent subtype of ADHD in both males and females as compared to the other ADHD subtypes followed by ADHD-HI, and ADHD-C (see Table 2).

\section{The prevalence of subtypes of ADHD in children by study setting}

The prevalence of ADHD was found to be $7.19 \%$ (95\% CI 5.59-9.19) for studies conducted in a communitybased setting and it was $8.74 \%$ (95\% CI 5.66-13.27\%) for studies conducted in hospital-based setting (see Table 2).

\section{Subgroup analysis by the tools used to measure ADHD}

The prevalence of ADHD was found to be slightly lower when measured using DSM (6.81\%) as compared to other instruments (7.62\%), although the observed difference across the tools used to measure ADHD was not statistically significant $(P=476)$ (see Table 2$)$. 


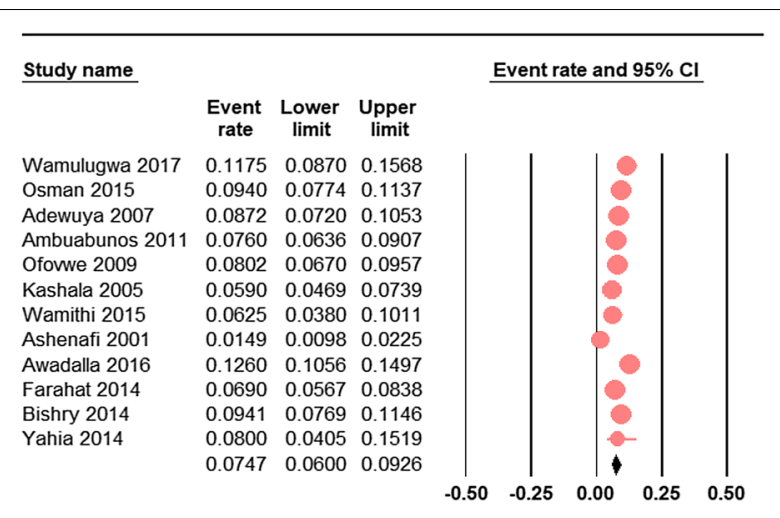

Keys: $P^{2}=90.29 \%, Q=114.25$, def $=11 ; P<0.0001 ;$ Based on random effect analysis

Fig. 2 The forest plot of the prevalence of ADHD in children and adolescents in Africa: a meta-analysis

\section{Subgroup analysis by the quality of studies}

When restricting the analysis to only 11 high-quality studies (Newcastle-Ottawa Scale, $\geq 8$ ), the magnitude of ADHD was 7.04\% (95\% CI 5.61-8.79) and was $11.25 \%$ (95\% CI 7.61-16.33) for both moderate and poor-quality studies combined (see Table 2).

\section{Publication bias}

Qualitatively (visual inspection), the funnel plot was symmetric and quantitatively, Egger's regression tests provided no evidence of substantial publication bias for the prevalence of ADHD in children and adolescents in Africa $(B=-3.64, \mathrm{SE}=2.84, P=0.229)$ (see Fig. 3 ).

\section{Discussion}

\section{Main findings}

This study is, to our knowledge, the first systematic review and meta-analysis on the prevalence of ADHD in children in Africa. We compiled data from 11,465 children selected from both community and clinical settings and estimated the prevalence of ADHD to be $7.47 \%$ (95\% CI 6.00-9.26). We observed a wide variation in the prevalence of ADHD across the countries ranging from 1.49 in Ethiopia to $11.75 \%$ in Uganda. The observed substantial variation in the prevalence of ADHD across the countries could be due to the methodological differences, the age of the child, perinatal complications, the instruments used to measure ADHD, sex of the participants, culture, and the sociodemographic status of the family as well as other comorbid mental and neurologic conditions.

The finding of the current meta-analysis $(7.47 \%)$ was consistent with the 9.2\% worldwide pooled prevalence estimate of ADHD reported by Ramtekkar et al. [43] in 2010 by including studies conducted using diagnostic instruments such as the Diagnostic and Statistical Manual of Mental Disorders (DSM) and the International Classification of Disease (ICD) criteria's. Likewise, our finding was also consistent with the $7.1 \%$ worldwide prevalence estimate of a recent meta-analysis conducted in 2015 by Thomas et al. [44].

However, our pooled prevalence estimates of ADHD in children and adolescents in Africa exceed the 5.3\% worldwide prevalence estimate of ADHD reported in 2007 by Polanczyk et al. [45]. The possible reason for a greater estimate of ADHD in Africa might be due to the variations in the characteristics of the studies included in the meta-analysis. We included studies conducted using any type of instrument as compared to Polanczyk et al. [45] which included studies conducted only using diagnostic instruments (prevalence reported according to DSM or the ICD criteria). In fact, the observed variation across the studies that used DSM/ICD and other instruments to measure ADHD was not statistically significant in our sensitivity analysis $(P=476)$. Moreover, the study population differed in a number of mental health-related and other environmental factors such as maternal substance used during and before pregnancy, the age of the child, perinatal complications, culture, other psychological and social factors as well as the sociodemographic status of the family and other comorbid mental and neurologic conditions among the study participants that are consistently associated with increased rates of ADHD in children and adolescent might contribute to the difference in the observed variation.

As expected, our stratified analysis showed that the estimate of ADHD in males (10.60\%) was considerably higher than the estimates in females (5.28\%) with a male:female ratio of 2.01:1. This ratio was lower than those reported by Ramtekkar et al. [43] which provided a greater prevalence of ADHD in males than females with a male:female ratio of $2.28: 1$. The lower male:female ratio in our study could be due to the prevalence estimates for male $(10.60 \%)$ in our review are slightly lower than those reported in Ramtekkar et al. [43] (15.7\%), but the estimate of females $(5.28 \%)$ was in line with those reported in Ramtekkar et al. [43] (7.5\%). These findings suggest males might be underdiagnosed in Africa.

Consistent with the previous meta-analytic study, the predominantly inattentive type (ADHD-I) is the most common subtype of ADHD in our meta-analysis [7]. The consistent nature of this subtype of ADHD may contributed to the greater prevalence [46]. Complementing this, evidence suggests that inattentive symptoms of ADHD remain relatively consistent over time $[46,47]$ whereas the other subtypes of ADHD are such as hyperactiveimpulsive symptoms are developmentally sensitive and tend to decline over time (while the feeling of restlessness 
Table 2 Subgroup analysis of all studies based on study setting, sex of the participants, tools used measure ADHD, subtypes of ADHD, and study quality

\begin{tabular}{|c|c|c|c|c|}
\hline Subgroups & Studies, $n$ & Prevalence (\%) & $95 \% \mathrm{Cl}$ & $\begin{array}{l}\text { Heterogeneity } \\
\text { between groups ( } P \\
\text { value) }\end{array}$ \\
\hline \multicolumn{5}{|l|}{ Setting } \\
\hline Community based & 9 & 7.19 & $5.59-9.19$ & \multirow[t]{2}{*}{0.439} \\
\hline Hospital based & 3 & 8.74 & $5.66-13.27$ & \\
\hline \multicolumn{5}{|l|}{ Gender } \\
\hline Males & 7 & 10.60 & $9.05-12.38$ & \multirow[t]{2}{*}{$<0.001$} \\
\hline Females & 7 & 5.20 & $4.38-6.36$ & \\
\hline \multicolumn{5}{|l|}{ Subtype of ADHD } \\
\hline Inattentive & 8 & 2.95 & $2.23-3.89$ & \multirow[t]{3}{*}{0.539} \\
\hline Hyperactive & 8 & 2.77 & $1.67-4.57$ & \\
\hline Combined & 8 & 2.44 & $2.01-2.96$ & \\
\hline \multicolumn{5}{|l|}{ Inattentive type by sex } \\
\hline Males & 6 & 4.05 & $3.11-5.27$ & \multirow[t]{2}{*}{0.004} \\
\hline Females & 6 & 2.21 & $1.61-3.03$ & \\
\hline \multicolumn{5}{|l|}{ Hyperactive type by sex } \\
\hline Males & 6 & 3.61 & $1.88-6.82$ & \multirow[t]{2}{*}{0.062} \\
\hline Females & 6 & 1.50 & $0.78-2.87$ & \\
\hline \multicolumn{5}{|l|}{ Combined type by sex } \\
\hline Males & 5 & 3.63 & $2.87-5.87$ & \multirow[t]{2}{*}{$<0.001$} \\
\hline Females & 5 & 1.52 & $1.11-2.08$ & \\
\hline \multicolumn{5}{|l|}{ Quality of studies } \\
\hline High & 10 & 7.04 & $5.61-8.79$ & \multirow[t]{2}{*}{0.041} \\
\hline Moderate and poor & 2 & 11.25 & $7.61-16.33$ & \\
\hline \multicolumn{5}{|c|}{ Tools used to measure ADHD } \\
\hline DSM & 2 & 6.81 & $5.67-8.15$ & \multirow[t]{2}{*}{0.476} \\
\hline Other & 10 & 7.62 & $5.92-9.75$ & \\
\hline
\end{tabular}

can persist) [46, 47]. Contrary to the findings of worldwide prevalence estimate of the meta-analysis conducted in 2015 by Skounti et al. [7] where ADHD-C was the second most type of ADHD, in our study the second most prevalent type of ADHD was the hyperactive-impulsive type (ADHD-HI), followed by combined (ADHD-C). The possible reason for the difference might the methodological difference across the studies included in the meta-analysis as well as the variations in other factors contributing to ADHD in children and adolescents.

Moreover, the current meta-analysis ADHD is more prevalent among males in all three subtypes including the predominantly inattentive type (ADHD-I), hyperactiveimpulsive type (ADHD-HI), and combined (ADHD-C). This is consistent with other study findings that ADHD is more prevalent among males in all three subtypes [4, 7, 11-13, 16-18]. In agreement with previous studies of the three types of ADHD, the prevalence of the predominantly inattentive type (ADHD-I) was greater in both males and females $[4,10-15]$.

\section{Difference between studies}

In the present meta-analysis, the variant among the 12 studies included in the final analysis led to a high level of heterogeneity. The methodological difference, sample size, the setting, the tools used, and the study populations differed on a number of characteristics, which may contributed to the variance in prevalence rates of ADHD in children and adolescents in Africa. For the purpose of further investigating the potential source of heterogeneity in the analysis of the prevalence rates of ADHD in children and adolescents in Africa, extensive sensitivity analysis based on the sex of participants, the tools used, the setting, and the quality of studies was done. This analysis revealed that the major causes for the variation across the studies were the sex of the participants and the subtypes of ADHD. Moreover, to make the results of our meta-analysis meaningful, we employed a random-effects model where summary effect estimates are more conservative than fixed-effects summaries in epidemiologic meta-analysis. 


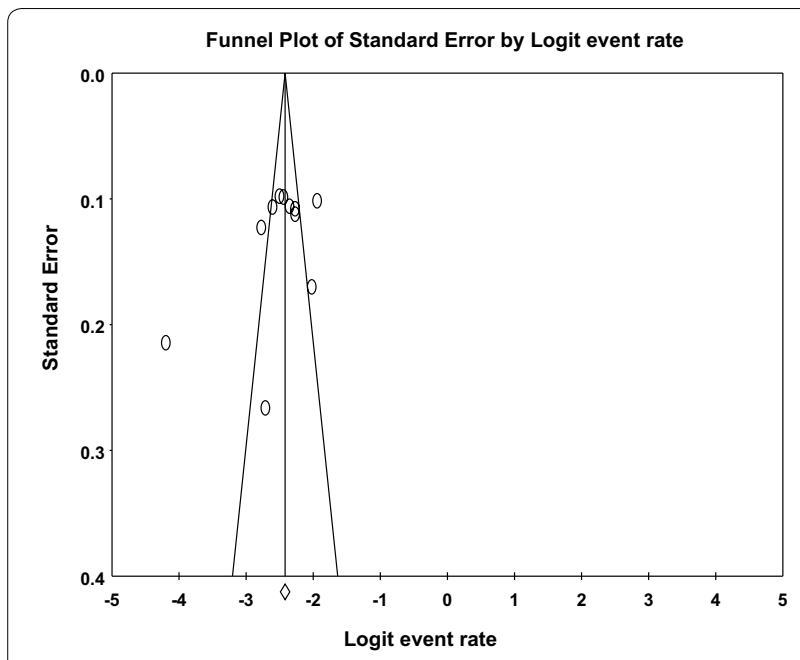

Fig. 3 The funnel plot for assessing publication bias

\section{Strength and limitations}

The current systematic review and meta-analysis has several strengths: first, to minimize the possible reviewer bias, data extraction and quality assessment were performed by two independent reviewers and we used a predefined search strategy to identify the possible studies to include in the study; second, to identify the small study effect and the risk of heterogeneity, we performed sensitivity and subgroup analysis; and third, we evaluated the quality of the included studies and the result from the assessment of the study quality indicated that the methodological quality was generally good. Nevertheless, we identified considerable heterogeneity among the studies which we considered as limitations of the current study.

\section{Conclusion}

In summary, results from this systematic review and meta-analysis suggest that (1) the prevalence of ADHD (7.47\%) was high; (2) the prevalence of ADHD was considerably greater in males than females with a male:female ratio of $2.01: 1$; (3) the predominantly inattentive type (ADHD-I) is the most common subtype of ADHD followed by ADHD-impulsive type (ADHD-HI) and combined (ADHD-C); (4) ADHD is more prevalent among males in all three subtypes; (5) among the three types of $\mathrm{ADHD}$, the prevalence of the predominantly inattentive type (ADHD-I) was greater in both males and females; (6) future studies should assess the possible reasons for gender difference in epidemiology of ADHD as well as the low male:female ratio in Africa as compared to worldwide findings. Finally, more attention should be paid to the prevention and treatment of ADHD in children and adolescents in Africa.

\begin{abstract}
Abbreviations
ADHD: Attention-deficit/hyperactivity disorder; DBRS: Disruptive Behavior Rating Scale; CASS: Conners-Wells Adolescent Self-Report Scale; DICA-R: Diagnostic interview for Child and Adolescents-Revised; SNAP-IV-C: Swanson, Nolan, and Pelham rating scale 4th revision; VARTRS: Vanderbilt ADHD Teacher Rating Scale; DSM-IV: Diagnostic and Statistical Manual of Mental Disorders, Fourth Edition.
\end{abstract}

\section{Acknowledgements}

No acknowledgments at this stage.

\section{Authors' contributions}

KY performed the search, data extraction, quality assessment, and draft and approval of the final manuscript. MA performed data extraction, quality assessment and approved the final manuscript. GA participated in discussion and consensus, conducted the analysis, write up, and approved the final manuscript. All authors read and approved the final manuscript.

\section{Funding}

The authors declare that there is no funding.

\section{Availability of data and materials}

All data generated or analyzed in this study are included in this article.

\section{Ethics approval and consent to participate}

Not applicable.

\section{Consent for publication}

Not applicable.

\section{Competing interests}

The authors declare that they have no competing interests.

\section{Author details}

${ }^{1}$ Research and Training Department, Amanuel Mental Specialized Hospital, Addis Ababa, Ethiopia. ${ }^{2}$ School of Public Health, Curtin University, Perth, western australia, Australia. ${ }^{3}$ Department of Psychiatry, Dilla University, Dilla, Ethiopia. ${ }^{4}$ Department of Psychiatry, Paulo's Millennium Medical College, Addis Ababa, Ethiopia.

Received: 23 October 2018 Accepted: 26 February 2020

Published online: 13 March 2020

\section{References}

1. Willcutt EG. The prevalence of DSM-IV attention-deficit/hyperactivity disorder: a meta-analytic review. Neurotherapeutics. 2012;9(3):490-9.

2. Berger I. Diagnosis of attention deficit hyperactivity disorder: much ado about something. IMAJ Isr Med Assoc J. 2011;13(9):571.

3. Connor DF, Doerfler LA. ADHD with comorbid oppositional defiant disorder or conduct disorder: discrete or nondistinct disruptive behavior disorders? J Atten Disord. 2008;12(2):126-34.

4. Pineda DA, Lopera F, Palacio JD, Ramirez D, Henao GC. Prevalence estimations of attention-deficit/hyperactivity disorder: differential diagnoses and comorbidities in a Colombian sample. Int J Neurosci. 2003;113(1):49-71.

5. American Psychiatric Association. Diagnostic statistical manual of mental disorder. 5th ed. Wahington, DC: American Psychiatric Association; 2013.

6. Simon V, Czobor P, Bálint S, Mészáros Á, Bitter I. Prevalence and correlates of adult attention-deficit hyperactivity disorder: meta-analysis. Br J Psychiatry. 2009;194(3):204-11.

7. Skounti M, Philalithis A, Galanakis E. Variations in prevalence of attention deficit hyperactivity disorder worldwide. Eur J Pediatr. 2007;166(2):117-23.

8. Alok S, Justin C. A review of the pathophysiology, etiology, and treatment of attention-deficit hyperactivity disorder (ADHD). Ann Pharmacother. 2013:48(2):209-25. 
9. Sharma A, Couture J. A review of the pathophysiology, etiology, and treatment of attention-deficit hyperactivity disorder (ADHD). Ann Pharmacother. 2014;48(2):209-25.

10. Gomez R, Harvey J, Quick C, Scharer I, Harris G. DSM-IV AD/HD: confirmatory factor models, prevalence, and gender and age differences based on parent and teacher ratings of Australian primary school children. J Child Psychol Psychiatry Allied Discipl. 1999;40(2):265-74.

11. Erşan EE, Doğan O, Doğan $S$, Sümer $H$. The distribution of symptoms of attention-deficit/hyperactivity disorder and oppositional defiant disorder in school age children in Turkey. Eur Child Adolesc Psychiatry. 2004;13(6):354-61.

12. Wolraich ML, Hannah JN, Baumgaertel A, Feurer ID. Examination of DSMIV criteria for attention deficit/hyperactivity disorder in a county-wide sample. J Dev Behav Pediatr. 1998;19(3):162-8.

13. Wolraich ML, Hannah JN, Pinnock TY, Baumgaertel A, Brown J. Comparison of diagnostic criteria for attention-deficit hyperactivity disorder in a county-wide sample. J Am Acad Child Adolesc Psychiatry. 1996;35(3):319-24.

14. Hudziak JJ, Heath AC, Madden PF, Reich W, Bucholz KK, Slutske W, Bierut LJ, Neuman RJ, Todd RD. Latent class and factor analysis of DSM-IV ADHD: a twin study of female adolescents. J Am Acad Child Adolesc Psychiatry. 1998;37(8):848-57.

15. Montiel-Nava C, Peña J, López M, Salas M, Zurga J, Montiel-Barbero I, Pirela D, Cardozo J. Estimaciones de la prevalencia del trastorno por déficit de atención-hiperactividad en niños marabinos. Rev Neurol. 2002;35(11):1019-24.

16. Baumgaertel A, Wolraich ML, Dietrich M. Comparison of diagnostic criteria for attention deficit disorders in a German elementary school sample. J Am Acad Child Adolesc Psychiatry. 1995:34(5):629-38.

17. Graetz BW, Sawyer MG, Hazell PL, Arney F, Baghurst P. Validity of DSM-IV ADHD subtypes in a nationally representative sample of Australian children and adolescents. J Am Acad Child Adolesc Psychiatry. 2001;40(12):1410-7.

18. Nolan EE, Gadow KD, Sprafkin J. Teacher reports of DSM-IV ADHD, ODD, and CD symptoms in schoolchildren. J Am Acad Child Adolesc Psychiatry. 2001;40(2):241-9.

19. Reviews UoYCf, Dissemination: systematic reviews: CRD's guidance for undertaking reviews in health care: University of York, Centre for Reviews \& Dissemination; 2009.

20. Moher D, Shamseer L, Clarke M, Ghersi D, Liberati A, Petticrew M, Shekelle P, Stewart LA, Group P-P. Preferred reporting items for systematic review and meta-analysis protocols (PRISMA-P) 2015 statement. Syst Rev. 2015;4(1):1

21. Stang A. Critical evaluation of the Newcastle-Ottawa scale for the assessment of the quality of nonrandomized studies in meta-analyses. Eur J Epidemiol. 2010;25(9):603-5.

22. Friedman-Weieneth $\mathrm{J}$, Doctoroff GL, Harvey EA, Goldstein LH. The Disruptive Behavior Rating Scale-Parent Version (DBRS-PV): Factor analytic structure and validity among young preschool children. J Atten Disord. 2009;13(1):42-55.

23. Gurley JR. Conners-Wells adolescent self report scale. In: Goldstein S, Naglieri JA, editors. Encyclopedia of child behavior and development. Boston: Springer US; 2011. p. 407-408.

24. Reich W. Diagnostic interview for children and adolescents (DICA). J Am Acad Child Adolesc Psychiatry. 2000;39(1):59-66.

25. Bussing R, Fernandez M, Harwood M, Wei H, Garvan CW, Eyberg SM, Swanson JM. Parent and teacher SNAP-IV ratings of attention deficit hyperactivity disorder symptoms: psychometric properties and normative ratings from a school district sample. Assessment. 2008;15(3):317-28.

26. Ofovwe CE, Ofovwe GE, Meyer A. The prevalence of attention-deficit/ hyperactivity disorder among school-aged children in Benin City, Nigeria. J Child Adolesc Ment Health. 2006;18(1):1-5.

27. American Psychiatric Association. Diagnostic and statistical manual of mental disorders-IV-TR. Washington, DC: American Psychiatric Association; 2000.

28. Borenstein M, Hedges LV, Higgins J, Rothstein HR. A basic introduction to fixed-effect and random-effects models for meta-analysis. Res Synth Methods. 2010;1(2):97-111.
29. Higgins JP, Thompson SG, Deeks JJ, Altman DG. Measuring inconsistency in meta-analyses. BMJ Br Med J. 2003;327(7414):557.

30. Adewuya AO, Famuyiwa OO. Attention deficit hyperactivity disorder among Nigerian primary school children prevalence and co-morbid conditions. Eur Child Adolesc Psychiatry. 2007;16(1):10-5.

31. Ambuabunos E, Ofevwe E, Ibadin M. Community survey of attentiondeficit/hyperactivity disorder among primary school pupils in Benin City. Nigeria. Ann Afr Med. 2011;10(2):91-6.

32. Ofovwe CE, Ofovwe GE, Meyer A. The prevalence of attention-deficit/ hyperactivity disorder among school-aged children in Benin City, Nigeria. Child Adolesc Psychiatry Ment Health. 2006;18(1):1-5.

33. Osman AM, Omer IM, Mohammed AA, Abdalla SE. The prevalence and factors affecting attention deficit hyperactivity disorder among school children in Khartoum State. Sudan J Paediatr. 2015:15(2):29.

34. Wamulugwa J, Kakooza A, Kitaka SB, Nalugya J, Kaddumukasa M, Moore S, Sajatovic M, Katabira E. Prevalence and associated factors of attention deficit hyperactivity disorder (ADHD) among Ugandan children; a crosssectional study. Child Adolesc Psychiatry Ment Health. 2017;11(1):18.

35. Kashala E, Tylleskar T, Elgen I, Kayembe K, Sommerfelt K. Attention deficit and hyperactivity disorder among school children in Kinshasa, Democratic Republic of Congo. Afr Health Sci. 2005;5(3):172-81.

36. Wamithi S, Ochieng R, Njenga F, Akech S, Macharia WM. Cross-sectional survey on prevalence of attention deficit hyperactivity disorder symptoms at a tertiary care health facility in Nairobi. Child Adolesc Psychiatry Ment Health. 2015;9(1):1.

37. Jenkins R, Othieno C, Ongeri L, Ogutu B, Sifuna P, Mboroki J, Omollo R. Attention deficit hyperactivity disorder symptom self-report in adults in Kenya and its associated risk factors, an analysis from a household survey in a demographic surveillance site. Glob Ment Health (camb). 2015;2:1-11.

38. Awadalla NJ, Ali O, Elshaer S, Eissa M. Role of school teachers in identifying attention deficit hyperactivity disorder among primary school children in Mansoura, Egypt/Rôle des enseignants dans l'identification du trouble de déficit de l'attention avec hyperactivité parmi les élèves du primaire à Mansoura, Égypte. East Mediterr Health J. 2016;22(8):586.

39. Farahat T, Alkot M, Rajab A, Anbar R. Attention-deficit hyperactive disorder among primary school children in Menoufia governorate, Egypt. Int J Fam Med. 2014;2014:257-369.

40. Bishry Z, Ramy HA, El-Shahawi HH, El-Sheikh MM, El-Missiry AA, El-Missiry MA. Screening for ADHD in a sample of Egyptian adolescent school students. J Atten Disord. 2018;22(1):58-655.

41. Yahia S, El-Hadidy M, El-Gilany A-H, Amdel-Hady D, Wahba Y, Al-Haggara M. Disruptive behavior in Down syndrome children: a cross-sectional comparative study. Ann Saudi Med. 2014;34(6):517.

42. Ashenafi Y, Kebede D, Desta M, Alem A. Prevalence of mental and behavioral disorders in children in Ethiopia. East Afr Med J. 2001;78(6):308-11.

43. Ramtekkar UP, Reiersen AM, Todorov AA, Todd RD. Sex and age differences in attention-deficit/hyperactivity disorder symptoms and diagnoses: implications for DSM-V and ICD-11. J Am Acad Child AdolesC Psychiatry. 2010;49(3):217-228.e211-213.

44. Thomas R, Sanders S, Doust J, Beller E, Glasziou P. Prevalence of attentiondeficit/hyperactivity disorder: a systematic review and meta-analysis. Pediatrics. 2015;135(4):e994.

45. Polanczyk G, de Lima MS, Horta BL, Biederman J, Rohde LA. The worldwide prevalence of ADHD: a systematic review and metaregression analysis. Am J Psychiatry. 2007;164(6):942-8.

46. Hart EL, Lahey BB, Loeber R, Applegate B, Frick PJ. Developmental change in attention-deficit hyperactivity disorder in boys: a four-year longitudinal study. J Abnorm Child Psychol. 1995;23(6):729-49.

47. Weyandt LL, Iwaszuk W, Fulton K, Ollerton M, Beatty N, Fouts H, Schepman S, Greenlaw C. The internal restlessness scale: performance of college students with and without ADHD. J Learn Disabil. 2003;36(4):382-9.

\section{Publisher's Note}

Springer Nature remains neutral with regard to jurisdictional claims in published maps and institutional affiliations. 